\title{
Editorial/Commentary
}

\section{Emergency medicine and medical administration: exploring the crossroads}

\author{
James Ducharme, MD
}

The physician does not learn everything he must know and master at high colleges alone... Therefore study each day without respite, investigate and observe diligently; despise notbing, and do not lightly put too much trust in yourself... Also, learn from those who are more experienced than you, for who can pretend to know everything?

- Paracelsus

In this issue, CFEM proudly launches its next series of themed articles. Over the past 2 years, led by Jonathan Sherbino, CFEM has published a collection of articles related to medical education. These articles enjoyed such enthusiastic reviews that we have chosen to publish a similar series of invited articles related to medical administration. And who better to act as editor for this series than Grant Innes, CFEM's editor emeritus? Grant has been asked to identify all of the topics for this series, invite experts in the field to participate, and oversee the editing of all submissions. Appropriately, the opening article to this series is entitled "Your Profession Needs You (Lessons in Medical Leadership)." ${ }^{1}$ The article is written by two long-standing leaders in emergency medicine administration in Canada, Tim Rutledge and Doug Sinclair. Both now have senior administration roles at their respective hospitals.

The DNA of an emergency physician allows survival and growth in an environment of chaos and stress, where decisions to save lives are made in seconds; it would seem that the apparent drudgery of hospital administration would be anathema to that DNA. Yet Rutledge and Sinclair rightly observe that leadership is also part of our DNA, for everyday we lead our teams at the bedside. They also make the very important distinction between leading and managing. The latter assumes attention to detail, monitoring of key performance indicators, and advancement of the status quo through conflict resolution and implementation of policies and procedures. Leadership, however, requires outward vision, charisma, strategic thinking, and the ability to unite diverse opinions into one common approach.

Some may say that leaders are born, not made; I support that belief to a large degree. Inherent ability goes nowhere without a proper construct, however, and that is taught through training and experience. Leadership is critical; many have felt that emergency medicine has had a leadership void for too long in too many places. Many of our best leaders go on to lead outside the emergency department (ED); the two authors of this issue's article are excellent examples of such career growth. We have to ensure, however, that our leaders, both inside and outside the EDs of Canada, continue to lead emergency medicine forward. The accumulated expertise from interactions outside our busy EDs can only further improve the administration of those departments.

Leaders have a responsibility to their constituents, in this case, emergency physicians. As Henry Kissinger said (available at: http://www.brainyquote.com/quotes/ quotes/h/henryakis166630.html). "Leaders are responsible not for running public opinion polls but for the consequences of their actions." Leadership requires internal certainty and confidence because "if you hope to lead your organization to prominence you must encourage dissent, disagreement, and truth from associates and search for the truth yourself." ${ }^{\prime 2}$ Being a leader does not mean that you inherently have the truth

From the Department of Emergency Medicine, McMaster University, Hamilton, ON.

Correspondence to: Dr. James Ducharme, 6711 Mississauga Road, Suite 404, Mississauga, ON L5N 2W3; paindoc22000@yahoo.com.

This article has been peer reviewed.

(c) Canadian Association of Emergency Physicians

CJEM 2013;15(2):63-64

DOI 10.2310/8000.2013.131125 
or are right; it means that you have to be able to bring everyone to that point. This means that as a leader, you have to be more willing than anyone else to recognize when you are wrong.

CFEM has asked Grant Innes to be such a leader and bring us all closer to an understanding of the complexities of medical administration with his selection of topics and expert contributors. That knowledge will empower all of us to better navigate the steps required to improve care within our hospitals or to interact with our peers at various committee meetings. It will also provide the ammunition to advocate more effectively for both our patients and emergency medicine itself. I hope you enjoy this new series as much as I anticipate I will.

Competing interests: None declared.

\section{REFERENCES}

1. Rutledge T, Sinclair D. Your profession needs you (lessons in medical leadership). CFEM 2013;15:00-00.

2. Bennis W. Why leaders can't lead. San Francisco: Jossey-Bass; 1989. 